\title{
Analisis Model Pembelajaran Reflektif Dalam Meningkatkan Hasil Belajar Mahasiswa Pada Mata Kuliah Pendidikan Pancasila
}

\author{
Apriyanti Widiansyah ${ }^{1}$, Rahmat Saputra ${ }^{2}$ \\ ${ }^{1}$ Universitas Bhayangkara Jakarta Raya/Fakultas Ilmu Pendidikan \\ e-mail: apriyanti.widiansyah@dsn.ubharajaya.ac.id \\ ${ }^{2}$ Universitas Bhayangkara Jakarta Raya /Fakultas Hukum \\ e-mail: rahmat.saputra@dsn.ubharajaya.ac.id
}

\begin{abstract}
Cara Sitasi: Apriyanti W, Rahmat S (2021), Analisis Model Pembelajaran Reflektif Dalam Meningkatkan Hasil Belajar Mahasiswa Pada Mata Kuliah Pendidikan Pancasila (2021) 21 (1), 19- 24 Retrieved from https://doi.org/10.31294/jc.v19i2
\end{abstract}

\begin{abstract}
The problems of students show that the values of Pancasila have been eroded in life in society, nation, and state. Therefore, it is necessary to find alternative solutions to various problems, by showing the importance of Pancasila education learning in educational institutions. This is intended to equip students to understand and try to fix some of these problems. In this case, it is necessary to have problem-solving through Pancasila Education learning activities by using the Reflective Learning Model. The research aims to determine the improvement of student learning outcomes in the Pancasila Education course, Faculty of Law, Bhayangkara University, Jakarta Raya. The research was conducted by doing learning actions, and how to make observations. Initial results are expected to bring awareness of students about the importance of Pancasila Education which aims to improve learning outcomes. Furthermore, several preparatory steps are arranged for observing the learning action. Researchers carried out observations of learning in the classroom with a Reflective learning model, by the actions planned in the study. Activities carried out by lecturers who have been provided with observation guidelines by recording all research activities from introduction, development, application, closing and writing additional information that has not occurred such as initiatives and reactions, both from researchers and students, as well as providing conclusions and general suggestions of actions which are conducted. The observation time was adjusted to the Pancasila Education course hours at the Faculty of Law, Bhayangkara University Jakarta Raya.
\end{abstract}

Keywords: Reflective_Learning_Model; Learning_Outcomes

\section{PENDAHULUAN}

Pancasila sebagai dasar negara dapat dikatakan sebagai status pokok yang memiliki landasan konstitusional dan berimplikasi yuridis. Berdasarkan sejarah bangsa Indonesia, sesungguhnya nilai-nilai Pancasila sebagai pandangan hidup bangsa telah terwujud dalam kehidupan bermasyarakat sebelum Pancasila sebagai dasar negara dirumuskan dalam satu sistem nilai. Sejak zaman dahulu, wilayahwilayah di nusantara mempunyai beberapa nilai yang dipegang teguh oleh masyarakatnya, di antaranya: 1) Percaya kepada Tuhan dan toleran; 2) Gotong royong; 3) Musyawarah; 4) Solidaritas atau kesetiakawanan sosial, dan lain sebagainya.

Timbulnya permasalahan yang melanda peserta didik (mahasiswa), memperlihatkan telah tergerusnya nilainilai Pancasila dalam kehidupan masyarakat, berbangsa dan bernegara. Oleh karena itu, perlu diungkap serta dicarikan solusi alternatif, salah satunya melalui pembelajaran pada mata kuliah pendidikan Pancasila.
Dengan demikian Dosen memegang peranan penting dalam proses belajar mahasiswa melalui pembelajaran. Untuk itu Dosen perlu menciptakan kondisi yang memungkinkan terjadinya proses interaksi yang baik dengan mahasiswa agar mereka dapat melakukan berbagai aktivitas belajar dengan efektif.

Dalam menciptakan interaksi yang baik diperlukan profesionalisme dan tanggung jawab yang tinggi dari seorang dosen dalam usaha untuk membangkitkan serta mengembangkan keaktifan mahasiswa dalam belajar sangat menentukan bagi keberhasilan pencapaiaan tujuan pembelajaran. Selanjutnya tingkat keaktifan belajar mahasiswa dalam suatu proses pembelajaran juga merupakan tolok ukur dari kualitas pembelajaran itu sendiri. Setidaknya terdapat 3 (tiga) faktor penyebab rendahnya hasil mahasiswa dalam proses pembelajaran yaitu: 1) mahasiswa kurang memiliki kemampuan untuk merumuskan gagasan sendiri, 2) mahasiswa kurang memiliki keberanian untuk menyampaikan 
pendapat kepada orang lain, dan 3) mahasiswa belum terbiasa bersaing menyampaikan pendapat dengan teman yang lain.

Kesalahan tersebut tidak bisa sepenuhnya dibebankaan kepada mahasiswa, namun terkadang dosen juga secara tidak sadar menerapkan sikap otoriter, menghindari pertanyaan dari mahasiswa, menyampaikan pembelajaran secara searah, menganggap mahasiswa sebagai penerima, pencatat dan pengingat.

Berdasarkan evaluasi pembelajaran pada perkuliahan Pendidikan Pancasila, maka pembelajaran dilaksanakan dengan memilih metode presentasi total dengan asumsi awal mahasiswa dapat aktif dalam pembelajaran serta sharing informasi. Berdasarkan evaluasi diperoleh pemahaman mahasiswa terhadap materi kurang, mahasiswa mengeluhkan pembelajaran membosankan, dan mata kuliah tidak menarik. Dari hasil evaluasi tersebut, diperlukan implementasi model pembelajaran yang dapat membangun daya tarik mahasiswa yaitu dengan menerapkan model pembelajaran reflektif.

Model pembelajaran reflektif bertujuan untuk meningkatkan kemampaun pemahaman mahasiswa, sehingga dapat terinternalisasi dalam diri, serta dapat di implementasikan dengan baik, dilandasai dasar teori kontruktivisme dan psikologis kognitif. Tujuan tersebut di perkuat oleh Sukmadinata (2004), pendekatan kompetensi, kontektual serta berbasis pengalaman, mencari dan bermakna. Soekamto (Trianto, 2013) menjelaskan bahwa model pembelajaran adalah kerangka konseptual, yang menggambarkan prosedur sistematis, dalam mengorganisasikan pengalaman belajar, untuk mencapai tujuan belajar tertentu, serta berfungsi sebagai pedoman bagi para perancang pembelajaran, dan para pengajar dalam merencanakan aktifitas belajar mengajar. Suprijono (2009) juga menyatakan bahwa model pembelajaran saat di artikan sebagai pola yang digunakan untuk peyusunan kurikulum, mengatur materi, serta memberi petunjuk kepada dosen di kelas. (Aprilia, 2016)

Menyadari pentingnya pembelajaran yang berpotensi mengembangkan kemampuan berfikir mahasiswa, peneliti memandang bahwa Model Pembelajaran Reflektif memiliki banyak kelebihan jika diterapkan sebagai alternatif pembelajaran Pendidikan Pancasila, sebagai upaya untuk mengembangkan kemampuan pemecahan masalah pembelajaran Pendidikan Pancasila.

Reflektif makna dasarnya merupakan pengkajian yang telah dialami oleh diri sendiri, sehingga terjadi kroscek antara hal yang dialami dengan yang dipelajari. Dengan demikian pembelajaran dalam konteks tersebut memberikan bandingan atau persamaan antara teori dengan kenyataan hidup yang dialami sehari-hari. (Marnita, 2017) Memberikan pengajaran melalui bebarapa potongan kertas sebagai media yang membuat konsep dasar, atau kata-kata kunci dari materi pembelajaran yang dapat direfleksikan oleh siswa". Memiliki arti bahwa, telah dialami dalam keseharian, sehingga hal yang dipelajari sesuai dengan yang telah dilakukan atau dialami oleh siswa. Cara tersebut merupakan penggunaan model pembelajaran Reflektif. (Istarani, 2011)

Dalam dunia pendidikan, pembelajaran reflektif telah dikembangkan oleh banyak ahli pendidikan. sehingga cukup banyak variasi pembelajaran reflektif yang dapat dipahami. Salah satu model pembelajaran reflektif merupakan pembelajaran dengan melibatkan kegiatan berpikir reflektif pada prosesnya. Sistem pembelajaran reflektif adalah sistem pembelajaran, dimana pendidik memberikan kesempatan kepada peserta didik untuk melakukan analisis atau pengalaman individual yang dialami, serta memfasilitasi pembelajaran dari pengalaman. Pembelajaran tersebut sangat berhubungan dengan pendekatan pembelajaran peserta didik secara realistik. (Novi Marliani, 2020)

Model Pembelajaran Reflektif merupakan pembelajaran dengan melibatkan kegiatan berfikir reflektif pada suatu prosesnya. Refleksi dalam konteks pembelajaran dirumuskan Boud, et al merupakan kegiatan intelektual dan afektif yang melibatkan pembelajar, dalam upaya mengekplorasi pengalaman mahasiswa dalam mencapai pemahaman serta apresiasi baru. Pada saat berfikir reflektif berlangsung, mahasiswa mempelajari hal-hal yang sedang dihadapi mahasiswa, berasumsi, menilai, bersikap, serta mengaplikasikan pemahamannya. Hal demikian sangat baik sekali, karena jika hal tersebut berlangsung secara berkelanjutan, maka pada akhirnya kegiatan berfikir tersebut akan sampai pada pemahaman yang lebih mendalam, perubahan pemikiran, dan akhirnya menyelesaikan permasalahan. Hmelo \& Ferrari (Song, Koszalka,dan Grabowski, 2005) menyimpulkan bahwa refleksi membantu siswa/mahasiswa untuk membangun keterampilan berfikir pada tingkat tertingginya. (Rohana \& Ningsih, 2016)

Belajar reflektif menurut Bain et al. (2002) memiliki 5 (lima) ciri yang menunjukkan hierarki proses berpikir antara lain: 1) Reporting (Pelaporan), 2) Responding (Menanggapi), 3) Relating (Terkait), 4) Reasoning (Penalaran), dan 5) Reconstructing (Rekonstruksi). Pada level reporting, dapat dicirikan dengan kemampuan mendeskripsikan situasi, fenomena, gejala ataupun masalah. Pada level responding dicirikan dengan kemampuan mengembangkan respon emosional terhadap masalah. Pada level relating dicirikan dengan 
kemampuan mengasosiasi berbagai fenomena dengan teori yang mendasari fenomena. Pada level reasoning dicirikan dengan kemampuan menjelaskan kejadian berdasarkan fakta peristiwa sistematis, sesuai dengan konsep metodologis pemecehan masalah. dan Pada level reconstructing dicirikan dengan kemampuan merencanakan tindakan penyelesaian masalah, berdasarkan perspektif teori serta pengalaman masa lalu. (Muhammad Rais, 2019)

Model pembelajaran reflektif melatih mahasiswa berpikir aktif serta reflektif, yang dilandasi pada proses berpikir ke arah beberapa kesimpulan definitif. (Agus Suprijono, 2010) Model pembelajaran reflektif membantu mahasiswa memahami materi berdasarkan pengalaman yang dimiliki, sehingga mahasiswa memiliki kemampuan menganalisis pengalaman pribadi dalam menjelaskan materi yang dipelajari khususnya pada mata kuliah Pendidikan Pancasila. Proses belajar yang berdasarkan pada pengalaman sendiri akan mengeksplorasi kemampuan dasar mahasiswa dalam memahami suatu peristiwa/ fenomena. Selain itu, kesiapan serta minat dalam mempelajari materi tersebut, juga meningkat karena hal yang akan dipelajari berasal dari pengalaman hidup sehari-hari mahasiswa. Penggunaan pengalaman mahasiswa sebagai bahan pelajaran, akan membentuk suasana belajar yang menyenangkan tanpa meninggalkan konteks belajar tersebut.

Pembelajaran reflektif dapat diterapkan pada semua kurikulum sebagai suatu sikap, mentalitas, serta pendekatan konsisten yang mewarnai seluruh pembelajaran. Model pembelajaran reflektif juga dapat diterapkan tidak hanya pada beberapa disiplin akademis, akan tetapi juga pada ranah non akademis seperti kegiatan ekstrakulikuler, program pelayanan masyarakat, maupun olah raga. (J. Drost, 2001)

Model pembelajaran reflektif merupakan pembelajaran dengan melibatkan kegiatan berpikir reflektif pada prosesnya. Refleksi merupakan kegiatan intelektual dan afektif yang melibatkan siswa dalam upaya mengekplorasi pengalaman siswa untuk memperoleh pemahaman serta beberapa apresiasi baru. (Putra, 2016)

Keuntungan pembelajaran reflektif antara lain mahasiswa menjadi aktif, serta dapat memperkirakan tindakan pada proses pembelajaran selanjutnya, dan membiasakan mahasiswa untuk melakukan refleksi secara mandiri pada pembelajaran berikutnya. Proses refleksi dengan waktu lama dan refleksi yang bersifat negative, dapat menjadi kelemahan pembelajaran reflektif. Contoh dampak negatif dari penggunaan waktu yang lama adalah mahasiswa cenderung akan merasa bosan, serta terhambatnya pembelajaran selanjutnya, sedangkan refleksi yang bersifat negatif akan memberikan pemahaman kepada mahasiswa yang tidak sesuai teori. (Abdi Prasetyo, Slamet Santosa, 2014)

Penelitian tindakan kelas dilakukan dalam 2 (dua) siklus, masing-masing dilaksanakan selama $2 \mathrm{x}$ pertemuan. Oleh karena itu, penelitian dilaksanakan selama $4 \mathrm{x}$ pertemuan. Masing-masing siklus terdiri dari perencanaan tindakan, pelaksanaan tindakan, observasi, serta refleksi.

\section{METODOLOGI PENELITIAN}

Penelitian dilakukan melalui proses kerja kolaborasi antara Dosen, Tim Ahli dan Peneliti di kampus. Kegiatan perencanaan awal dimulai dari melakukan studi pendahuluan. Pada kegiatan tersebut juga mendiskusikan cara melakukan tindakan pembelajaran dan bagaimana melakukan pengamatannya. Diskusi kerjasama antara Dosen, Peneliti dan Tim Ahli dikembangkan dalam setiap penyusunan perencanaan berikutnya, dan diskusi berdasarkan hasil diskusi yang telah dilakukan.

Secara sistematis siklus penelitian tindakan kelas yang dimaksud sebagai berikut:

Secara sistematis siklus penelitian tindakan kelas yang dimaksud sebagai berikut:

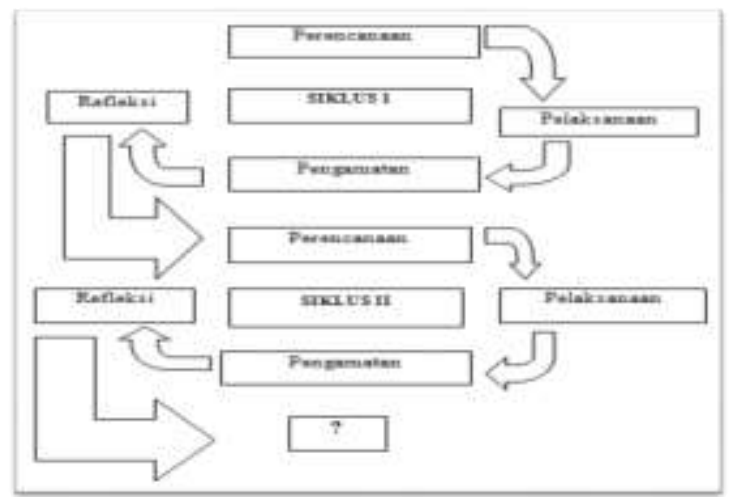

Model Tahapan Pelaksanaan PTK (Suyadi, 2013)

Penelitian dilaksanakan di Fakultas Hukum, Universitas Bhayangkara Jakarta Raya. Keadaan gedung kampus sudah permanen, pencahayaan ruangan cukup baik, sehingga memungkinkan peneliti menggunakan metode pembelajaran yang telah direncanakan.

Waktu penelitian mulai direncanakan bulan Oktober 2019 s/d September 2020. Subjek penelitian yakni Dosen dan Mahasiswa Semester 1 Fakultas Hukum, Universitas Bhayangkara Jakarta Raya pada kelas 1 A2 sebanyak 39 orang, kelas 1 A3 sebanyak 35 orang, kelas 1 A4 sebanyak 37 orang, dan kelas 1 B1 sebanyak 22 orang, kelas 1 B2 Sebanyak 18 orang, kelas $1 \mathrm{C} 1$ sebanyak 34 orang, serta kelas $1 \mathrm{C} 2$ 
sebanyak 31 orang.

PTK direncanakan dalam 2 (dua) siklus. setiap siklus akan dilaksanakan secara bertahap sesuai dengan perubahan dan target yang ingin dicapai. Siklus pertama merupakan awal dari pembelajaran Pendidikan Pancasila. Siklus selanjutnya merupakan perbaikan dari hasil refleksi siklus sebelumnya, sehingga perubahan dan target yang ingin dicapai dapat terlihat berhasil atau tidaknya. Untuk mengukur keberhasilan belajar mahasiswa dilakukan tes melalui lembar kerja mahasiswa dan lembar penilaian individu.

Adapun Instrument penelitian yang digunakan untuk mengukur fenomena alam ataupun sosial yang diamati di antaranya: 1) Pedoman Observasi; 2) Tes;

3) Dokumentasi; 4) Wawancara.

Teknik analisis data penelitian adalah data kualitatif yang diolah dengan analisis deskriptif sedangkan data kuantitatif diolah dengan bentuk paparan narasi yang mengambarkan kualitas pembelajaran yang dilaksanakan dan pada saat mahasiswa melaksanakan tes. Kegiatan tersebut berupaya memunculkan makna dari setiap data yang didapat, sehingga data tersebut tidak hanya bersifat deskriptif. Dalam penelitian dengan pendekatan kualitatif, pengolahan dan analisis data dilakukan secara terus-menerus dari awal sampai akhir pelaksanaan program tindakan.

\section{HASIL DAN PEMBAHASAN}

\section{Siklus I}

Rata-rata aktivitas mahasiswa pada siklus I pertemuan 1 dan 2

\begin{tabular}{|cl|c|c|c|}
\hline \multirow{2}{*}{ Aspek yang diamati } & \multicolumn{2}{|c|}{ Pertemuan } & $\begin{array}{c}\text { Rata-rata } \\
\text { (\%) }\end{array}$ \\
\cline { 3 - 5 } & $\begin{array}{c}\mathbf{1} \\
(\boldsymbol{\%})\end{array}$ & $\begin{array}{c}\mathbf{2} \\
(\boldsymbol{\%})\end{array}$ & \\
\hline 1. & Mengajukan pertanyaan & 17,03 & 17,01 & $17,02 \%$ \\
\hline 2. & $\begin{array}{l}\text { Menanggapi respon } \\
\text { mahasiswa lain }\end{array}$ & 17,64 & 13,86 & $15,75 \%$ \\
\hline 3. & $\begin{array}{l}\text { Menjawab pertanyaan } \\
\text { dosen }\end{array}$ & 20,45 & 13,96 & $17,20 \%$ \\
\hline 4. & $\begin{array}{l}\text { Memperhatikan } \\
\text { penjelasan dosen }\end{array}$ & 13,96 & 20,45 & $17,20 \%$ \\
\hline 5. & Diskusi kelompok & 13,86 & 17,64 & $15,75 \%$ \\
\hline 6. & Diskusi kelas & 17,01 & 17,03 & $17,02 \%$ \\
\hline
\end{tabular}

Sumber: Olah Data 2020

Berdasarkan tabel di atas tentang Rata-rata aktivitas mahasiswa pada siklus I pertemuan 1 dan 2 pada mata Pendidikan Pancasila pada kelas: 1 A2, 1 A3, 1A4, 1 B1, 1 B2, 1 C1, 1 C2 (Sebanyak 7 kelas). Beberapa aspek yang di amati dari 7 (tujuh) kelas tersebut, antara lain: 1) Mengajukan pertanyaan $(17,02 \%), 2)$ Menanggapi respon mahasiswa lain $(15,75 \%), 3)$ Menjawab pertanyaan dosen $(17,20 \%)$, 4) Memperhatikan penjelasan dosen $(17,20 \%), 5)$ Diskusi kelompok $(15,75 \%), 6)$ Diskusi kelas $(17,02 \%)$

\section{Refleksi}

Pembelajaran pada siklus I dilakukan agar mahasiswa dapat memahami materi Pendidikan Pancasila dengan Model Pembelajaran Reflektif. Pada siklus I belum dilaksanakan secara optimal, karena mahasiswa belum terbiasa dengan Model Pembelajaran Reflektif, sehingga aktivitas yang diharapkan masih belum maksimal. Aktivitas mahasiswa dalam mengikuti pembelajaran masih kurang memahami dengan model pembelajaran yang dilaksanakan oleh dosen, karena mahasiswa belum terbiasa menggunakan Model Pembelajaran Reflektif yang masih baru dan asing bagi mahasiswa.

\section{Siklus II}

Rata-rata aktivitas mahasiswa pada siklus II pertemuan 3 dan 4

\begin{tabular}{|ll|c|c|c|}
\hline \multirow{2}{*}{ Aspek yang diamati } & \multicolumn{2}{|c|}{ Pertemuan } & $\begin{array}{c}\text { Rata-rata } \\
(\%)\end{array}$ \\
\cline { 3 - 5 } & & $\begin{array}{c}\mathbf{3} \\
\mathbf{( \% )}\end{array}$ & $\begin{array}{c}\mathbf{4} \\
(\boldsymbol{\%})\end{array}$ & \\
\hline 1. & Mengajukan pertanyaan & 19,19 & 17,95 & $18,57 \%$ \\
\hline 2. & Menanggapi respon mahasiswa lain & 18.99 & 18,58 & $9,69 \%$ \\
\hline 3. & Menjawab pertanyaan dosen & 17,38 & 21,48 & $19,43 \%$ \\
\hline 4. & Memperhatikan penjelasan dosen & 17,33 & 20,99 & $19,16 \%$ \\
\hline 5. & Diskusi kelompok & 11,97 & 9,35 & $10,66 \%$ \\
\hline 6. & Diskusi kelas & 15,07 & 10,95 & $13,01 \%$ \\
\hline
\end{tabular}

Sumber: Olah Data 2020

Berdasarkan tabel di atas tentang Rata-rata aktivitas mahasiswa pada siklus II pertemuan 3 dan 4 pada mata Pendidikan Pancasila pada kelas: 1 A2, 1 A3, 1A4, 1 B1, 1 B2, 1 C1, 1 C2 (Sebanyak 7 kelas). Beberapa aspek yang di amati dari 7 (tujuh) kelas tersebut, antara lain: 1) Mengajukan pertanyaan $(18,57 \%)$, 2) Menanggapi respon mahasiswa lain $(9,69 \%), 3)$ Menjawab pertanyaan dosen $(19,43 \%), 4)$ Memperhatikan penjelasan dosen $(19,16 \%)$, 5) Diskusi kelompok (10,66\%), 6) Diskusi kelas $(13,01 \%)$.

\section{Refleksi}

Pada siklus II tidak terdapat hambatan yang berarti, tetapi perlu ditingkatkan lagi pembelajaran dengan menggunakan dengan Model Pembelajaran Reflektif untuk ikut berpartipasi dalam KBM.

Penelitian yang bertujuan agar mahasiswa dapat memahami materi Pendidikan Pancasila dengan Model Pembelajaran Reflektif, telah dilaksanakan 2 
siklus dalam 4 kali pertemuan, dan setiap siklus terdiri dari 2 kali pertemuan. Penelitian dilaksanakan pada bulan Oktober 2019 sampai September 2020. Adapun hasil penelitian secara keseluruhan dapat dilihat pada tabel berikut:

\section{Rata-rata aktivitas mahasiswa pada siklus I dan II untuk 4 pertemuan}

\begin{tabular}{|cl|c|c|c|}
\hline \multirow{2}{*}{ Aspek yang diamati } & \multicolumn{2}{|c|}{ Siklus } & $\begin{array}{c}\text { Rata-rata } \\
(\%)\end{array}$ \\
\cline { 3 - 5 } & & $\begin{array}{c}\text { I } \\
(\%)\end{array}$ & $\begin{array}{c}\text { II } \\
(\%)\end{array}$ & \\
\hline 1. & Mengajukan pertanyaan & 17,02 & 18,57 & $17,79 \%$ \\
\hline 2. & $\begin{array}{l}\text { Menanggapi respon mahasiswa } \\
\text { lain }\end{array}$ & 15,75 & 9,69 & $12,72 \%$ \\
\hline 3. & Menjawab pertanyaan dosen & 17,20 & 19,43 & $18,31 \%$ \\
\hline 4. & Memperhatikan penjelasan dosen & 17,20 & 19,16 & $18,18 \%$ \\
\hline 5. & Diskusi kelompok & 15,75 & 10,66 & $13,20 \%$ \\
\hline 6. & Diskusi kelas & 17,02 & 13,01 & $15,01 \%$ \\
\hline
\end{tabular}

Sumber: Olah Data 2020

Berdasarkan tabel di atas tentang Rata-rata aktivitas mahasiswa pada siklus I dan II untuk 4 pertemuan, pada mata Pendidikan Pancasila pada kelas: 1 A2, 1 A3, 1A4, 1 B1, 1 B2, 1 C1, 1 C2 (Sebanyak 7 kelas). Beberapa aspek yang di amati dari 7 (tujuh) kelas tersebut, antara lain: 1) Mengajukan pertanyaan $(17,79 \%), 2)$ Menanggapi respon mahasiswa lain $(12,72 \%), 3)$ Menjawab pertanyaan dosen $(18,31 \%)$, 4) Memperhatikan penjelasan dosen $(18,18 \%)$, 5) Diskusi kelompok $(13,20 \%)$, 6) Diskusi kelas $(15,01 \%)$.

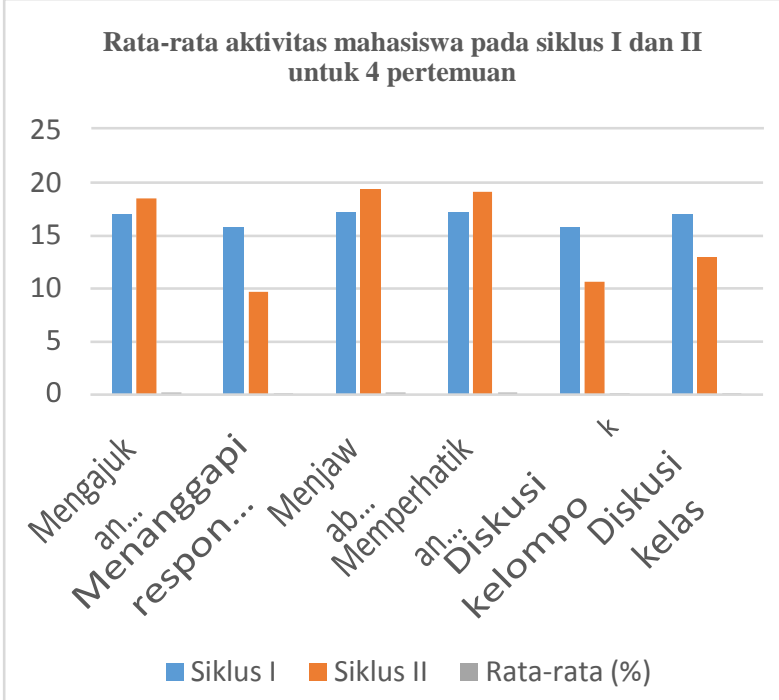

Hasil penelitian dan pembahasan dapat disimpulkan bahwa penerapan Model Pembelajaran Reflektif untuk meningkatkan pemahaman mahasiswa tentang Pendidikan Pancasila pada kelas: 1 A2, 1 A3, 1A4, 1 B1, 1 B2, 1 C1, 1 C2 (Sebanyak 7 kelas) telah memberikan hasil berimbang antara siklus I dan siklus II dalam 4 pertemuan. Hal demikian dapat dibuktikan dengan perolehan nilai rata-rata pada setiap siklus yang di dapat.

\section{KESIMPULAN}

Berdasarkan tindakan siklus I dan siklus II dengan 4 pertemuan yang telah dilakukan pengamatan dalam penelitian, maka dapat disimpulkan bahwa dengan dengan Model Pembelajaran Reflektif dapat meningkatkan hasil belajar mahasiswa dalam proses pembelajaran, khususnya materi Pendidikan Pancasila pada Fakultas Hukum Universitas Bhayangkara Jakarta Raya.

\section{REFERENSI}

Abdi Prasetyo, Slamet Santosa, M. (2014). Penerapan Model Pembelajaran Reflektif pada Pembelajaran Biologi terhadap Hasil Belajar Siswa Kelas X SMA Negeri Colomadu Tahun Pelajaran 2012/2013. BIO-PEDAGOGI, 3(2010), 1-10.

Agus Suprijono. (2010). Cooperative Learning Teori dan Aplikasi PAIKEM. Yogyakarta: Pustaka Pelajar.

Aprilia, N. (2016). Implementasi Model Pembelajaran Reflektif untuk Meningkatkan Kemampuan Pemahaman Mahasiswa Pendidikan Biologi pada Mata Kuliah Strategi Pembelajaran di Program Studi FKIP Universitas Ahmad Dahlan. Jurnal Bioedukatika, 4(1), 27.

Istarani. (2011). Model Pembelajaran Inovatif. Medan: Media Persada.

J. Drost. (2001). Ignation Pedagogy: A Practical Approach. Jakarta.

Marnita, M. (2017). Model Pembelajaran Reflektif Learning Untuk Meningkatkan Keterampilan Proses Sains Dan Penguasaan Konsep Siswa Pokok Bahasan Kalor Dan Perpindahannya Di Kelas Vii Mtsn. Jurnal Pendidikan Almuslim, 5(1), 23-29.

Muhammad Rais, F. A. (2019). Pembelajaran Reflektif Seni Berpikir Kritis, Analitis Dan Kreatif (ke-1). Makassar: Badan Penerbit Universitas Negeri Makassar.

Novi Marliani, N. (2020). Komunikasi Matematika Dilihat Dari Model Pembelajaran Reflektif Berbasis Matematika Realistik. SINASIS (Seminar Nasional Sains), 1(1), 403-411.

Putra, F. G. (2016). Pengaruh Model Pembelajaran Reflektif dengan Pendekatan Matematika Realistik Bernuansa Keislaman terhadap Kemampuan Komunikasi Matematis. $A L$ Jabar: Jurnal Pendidikan Matematika, 7(2), 
203-210.

Rohana, \& Ningsih, Y. L. (2016). Model Pembelajaran Reflektif Untuk Meningkatkan Kemampuan Pemecahan Masalah Matematis Mahasiswa Calon Guru. Jppm, 9(2), 145-158.

\section{PROFIL PENULIS}

Penulis 1

Dr. Apriyanti Widiansyah, S.S., M.Pd adalah Dosen Tetap Program Studi Pendidikan Guru Sekolah Dasar dan Kepala Satuan Penjamin Mutu Fakultas Ilmu Pendidikan Universitas Bhayangkara Jakarta Raya.

Penulis 2

Dr. (c) Rahmat Saputra, SH.,MH juga merupakan Dosen Tetap Program Studi Ilmu Hukum Fakultas Hukum Universitas Bhayangkara Jakarta Raya. 